\title{
Scaffolding Speaking Tasks Using Videoblog Portfolio in an ESL Classroom
}

\author{
Asyraf Shuib, Lilliati Ismail", Umi Kalthom Abdul Manaf \\ Faculty of Educational Studies, Universiti Putra Malaysia, Malaysia
}

Received October 27, 2019; Revised December 2, 2019; Accepted December 24, 2019

Copyright $\mathrm{C} 2020$ by authors, all rights reserved. Authors agree that this article remains permanently open access under the terms of the Creative Commons Attribution License 4.0 International License

\begin{abstract}
Video blogging (vlogging) was chosen in this study as a language learning tool. The idea of studying video blogging stems from Vygotsky's socio-constructivism theory and Siemens' theory of networking, connectivism. The theories underpinned the study and were applied in a project based on instruction, which gave emphasis on student-centred learning. Assuming the roles of instructional designers, the researchers initiated this project to address instructional needs by integrating technological media to facilitate learners' speaking fluency development. This case study explored the network and collaborative traits that vlogging could bring in learning a second language. Data was collected from field observations, a qualitative document and a focus group interview. The researchers then analysed the qualitative data to identify the scaffolding techniques used by the participants of the study. The researchers coded and clustered the scaffolding techniques into themes based on two types of scaffoldings; (i) sensory scaffoldings, and (ii) interactive scaffoldings. The findings show that learners employed scaffolding techniques to facilitate learning amongst peers and knowledgeable others throughout the vlog portfolio project.
\end{abstract}

Keywords Video Blogging, Video-based Learning, Project Based Learning, Scaffolding, E-learning

\section{Introduction}

Today, the widespread use of smartphones and tablet computers with internet connectivity has enabled every individual to communicate via mobile gadgets, normalising interactions in the vast linguistically compelling realms of the internet and social network. Moreover, great numbers of innovations in the field of Information Communication Technology (ICT) have given rise to many social media applications.
Among the most preferred social networking sites of the internet are Facebook, Twitter, YouTube, MySpace, Whatsapp and others (Abdelraheem \& Ahmed, 2018). Virtual platforms have become one of the most notable phenomena that have afforded seamless mass communication. Inadvertently, the use of e-portfolios has also become mote increasingly apparent among digital natives today (Lim, 2013). Youths especially, have been taking part in global communication addressing myriad topics ranging from societal to global issues by video blogging (vlogging) their ideas and opinions. Unlike other media tools, video blog uniquely paves the opportunities for network and conversation between the video blogger (vlogger) or the author and the viewers. Viewers can comment on vlogs and vloggers can comment on each other's profiles which lead to interactions (Jap, 2007).

The power of social networking is great due to the notion that over 1 billion people are now online worldwide. They are often referred to as 'netizens' or the 'digital natives. Now, people are more open to share their lives across the Internet than ever before (Malita \& Martin, 2010; Richardson, 2009).

\subsection{Problem Statement}

Although English is the official second language in Malaysia, surveys still show that common problems in communication among graduates include poor speaking skills, inability to comprehend questions, and lack of interaction skills (Shahariah Saleh \& Murtaza, 2018; Alias, Sidhu, \& Chan, 2013). Scholars suggested that communicating in English for a second language speaker be a challenging feat due to many factors attributed with to the fear of speaking English such as language anxiety, limited vocabulary, and lack of exposure to communicate in the language (Pertaub, Slater, \& Barker, 2002; Tanveer, 2007). Darmi \& Albion, (2013) and Hassan \& Selamat (2002) argued that learners do not receive enough support for their learning especially in nurturing listening and 
speaking to improve communication in the second language (L2), hence there is minimal exposure to practice with a meaningful communicative context. In order to reduce this problem, both educators and scholars need to explore the alternative approaches to improve teaching and learning especially for communication skills in ESL classrooms. Many studies have investigated the potentials of using Web 4.0 tools such as blogs and social media to enhance language learning, (Gromik, 2015; Hussain, Cakir, \& Candeger, 2018; Insyirah et al., 2018; Kessler, 2018). Currently, studies on how $21^{\text {st }}$ century learning tools could be utilised to maximise learning outcomes is mostly on teaching writing skills (e.g., Bakar \& Ismail, 2007; Yunus, Nordin, Salehi, Embi, \& Salehi, 2013) that outnumber speaking skills. Therefore, the researchers carried out a study to investigate how technological advancement could benefit learners' spoken language.

Attempting to communicate a new language individually can be daunting for English Second Language (ESL) and English Foreign Language (EFL) learners. With the right amount of support and the appropriate assistive tools, learners could achieve better L2 performance. The concepts of scaffolding and connectivism underpinned the study.

\subsection{Research Question}

This paper sought to answer one research question; What are the scaffolding techniques employed by learners during peer reviewing of the vlog portfolio?

\section{Literature Review}

Studies have shown evidence that social network can provide people with many affordances when used in educational settings (Ferdig, Pytash, Kosko, Gandolfi, \& Mathews, 2016, AbdelRaheem, 2015; Alqahtani \& Mohammad, 2015). Scholars have investigated how convenient personalized and collaborative learning with mobile social network applications are besides increasing students' motivation (Alvarez, Alarcon, \& Nussbaum, 2011; Chiang, Yang \& Hwang, 2014). However, there is a dearth of studies on the use of social media as a learning tool to teach speaking in the Malaysian context.

Sharples and Domingue (2016) argued that although it is possible to attend different courses and seminars on public speaking, opportunities to practice and receive feedback from tutors or peers under realistic conditions are limited. The study conducted by Gorkaltseva et al. (2015) also argued that oral fluency was severely hindered because of the learners' low motivation for verbal interaction, which is due to learners' lack of pragmatic competence and lack of linguistic competence. In a similar vein, Gromik (2015) and Chen (2006) found that EFL learners do not have adequate opportunity to use the target language during class time.

\subsection{Scaffolding in L2 Learning}

Educators and researchers have used the concept of scaffolding as a metaphor to describe and explain the role of adults or more knowledgeable peers in guiding learning and development (Nguyen, 2013; Verenikina, 2008; Krause, Bochner \& Duchesne 2003; Hammond 2002; Daniels 2001; Stone 1998). Vygotsky (1978) through the concept of the Zone of Proximal Development (ZPD) in the Socio-constructivism theory posited that mediation is not limited to that of only teachers or adults, but peer scaffolding is also important for internalisation of knowledge, development of skills and learning progress. It was further explained that when a child is in interaction with people and in cooperation with his peers, learning a series of internal developmental processes occurs. Fundamental communicative language skills such as listening and speaking would progress through social interaction.

Scaffolding emphasises on learner interaction to facilitate learning in a common social domain. The researchers designed a video-based project called the vlog portfolio using a social media to stimulate sensory scaffolding with the use of peer support and later prompt interactive scaffolding among learners and their peers. Scaffolding also acts as "the mediator adjusting the complexity and maturity of the teaching interaction to facilitate the child mastery of the task; providing support when necessary and providing encouragements and prompts to the child to move ahead when ready" (Ranjbar \& Ghonsooly, 2017; Lidz 1991, p. 80). In a wider sense, scaffolding is "a form of support for the development and learning of children and young people" (Pishar., 2017; Verenikina, 2008; Rasmussen 2001;). Scaffolding in this research is operationalised as peer reviewing or peer scaffolding. As learners engage during peer reviewing they were expected to generate several types of feedback, which are regarded as different techniques of scaffolding. In short, scaffolding is giving the student a more active role in their learning as opposed to teacher-directed learning. Since the aim of scaffolding is to move learners through stages of other-regulation to self-regulation (Ranjbar \& Ghonsooly, 2017) which can lead a way for learner's self-regulation and autonomy.

Wells (1999) stated that a teaching and learning event should enable learners to carry out tasks which they would not have been able to manage on their own. Next, it should bring the learners to a state of competence which will enable them eventually to complete such a task on their own. Finally it must be followed by evidence of the learners having achieved some greater level of independent competence as a result of the scaffolding experience (Verenikina, 2008; Wells 1999 pp 221). 
Table 1. Forms of scaffolding cited from (Wells, 1999)

\begin{tabular}{|c|c|c|}
\hline \multicolumn{3}{|c|}{ Forms of Scaffolding } \\
\hline Sensory & Interactive & Graphic \\
\hline $\begin{array}{l}\text { Videos and films } \\
\text { Models and figures } \\
\text { Demonstrations and modelling } \\
\text { Real-life objects }\end{array}$ & $\begin{array}{l}\text { Pairs } \\
\text { Small groups } \\
\text { Using cooperative structures } \\
\text { With coach or mentor } \\
\text { Discussions } \\
\text { Interviews } \\
\text { With the internet, app, or software program }\end{array}$ & $\begin{array}{l}\text { Infographics } \\
\text { Graphic organizers } \\
\text { Charts } \\
\text { Tables } \\
\text { Graphs } \\
\text { Timeline }\end{array}$ \\
\hline $\begin{array}{l}\text { Making connection between ideas, } \\
\text { Contextualising abstract ideas } \\
\text { through objects, } \\
\text { Acquiringnew knowledge }\end{array}$ & $\begin{array}{l}\text { Synthesising information } \\
\text { Planning action } \\
\text { Engaging in an on-going process } \\
\text { Acquiring knowledge through interaction } \\
\text { whether in-person or virtual }\end{array}$ & $\begin{array}{l}\text { Acquiring knowledge through numerical data } \\
\text { Producing ideas in graphic organizers and } \\
\text { interactive tables } \\
\text { Recognising trends and patterns } \\
\text { Seeing cause-effect relationships }\end{array}$ \\
\hline
\end{tabular}

Gordon Wells (1999) categorised scaffoldings into three types; sensory, interactive and graphic (Refer Table 1) and the researchers subscribed to his definitions. Thus, a qualitative document was designed for participants to record their feedback and peer reviewing sessions were carried out to observe interaction meaning to scaffold the learning process.

\subsubsection{Sensory Scaffoldings}

Sensory scaffoldings are stimulated by the senses such as audio visual stimulus. For this study, learners' feedback was derived from observations of the peers' video blog. Feedback was recorded using the qualitative document known as the speech-review-report (SRR). When filling up this form learners listened to and analysed the features of the utterances such as fillers, pronunciation, grammar, and vocabulary.

\subsubsection{Interactive Scaffoldings}

Interactive scaffolding is derived based on the moderated speech reviewing interviews. After filling up the report, feedback for the learners was given orally by their peers in an interactive discussion. During this recorded discussion, the researchers observed, monitored and took field notes of the discussion with minimal interruptions. Necessary prompts were given if they were required to further probe the respondents' feedback.

\subsection{Connectivism}

Connectivism is a learning approach with the advancement of Information Communication Technology (ICT) that gives emphasis on networking and learning. Connectivism presents itself as a pedagogical approach that affords learners the ability to connect with each other via social networking or collaboration tools. It is believed that learning today has become so complex that "we need to rely on a network of people (and, increasingly technology) to store, access, and retrieve knowledge and motivate its use" (Siemens, 2008).
Learning is viewed as multi-faceted and particular tasks defining which approach to learning is most appropriate to the learner (Siemens, 2005). When learning is put in a technological sphere, more access is granted towards teaching and learning. Learning through any technological device and virtual environment such as social media and network is the main themes of Connectivism.

In this study, collaboration between learners is seen as a behavioural networking. Learners are supporting one another to achieve their goals through the peer-speech-report. When learners post their video blog speech, feedback can be given instantly in the form of comments, viewers' feedback or even peer review. This is parallel with the concept of Connectivism where networking is established when learners interact with one another along with the teacher to build a positive learning community through technological media.

\section{Methodology}

A qualitative design was employed in the current study; the researchers used a single case study as the research framework (Cresswell, 2014; Gustafsson, 2017; Y in 2003). The researchers investigated the application of a video blog portfolio in higher education college involving 19 participants (5 males and 14 females) aged 18-20 years old for a period of 10 weeks.

\subsection{The Participants}

The participants were purposively sampled and the sample criteria are, participants must be students who only possess intermediate or advanced level of proficiency in English. This was determined through their MUET band scores (Bands 3-5). They were non-native speakers of English, which in this case, a majority of the students' native languages are Chinese or Malay. The participants were all enrolled in the same English Second Language proficiency course, "Structure and Speaking". The 
coordinator of the course assisted the researchers to identify the participants. A module was developed to guide the participants to conduct the project. The module was aligned with the instructional needs with guidance and feedback from the course instructor and literature (Donnelly \& Fitzmaurice, 2005; Remesh, 2017). It was treated as a manual to guide learners in completing their weekly video blog tasks, and as a supplementary instruction to their formal instruction in their "Structure and Speaking" class.

\subsection{Data Collection Methods}

Because the current study utilized a qualitative design, the data are primarily verbal responses derived from the qualitative document, field observations and focus group interview. The qualitative document and field observation were administered weekly throughout the duration of the study, whereas the focus group interview was carried out at the end of the study. The researchers became the main instrument of the study to collect and interpret the data.

\subsection{Data Analysis}

All verbal responses were recorded and transcribed verbatim. The researchers then analyzed the transcripts to encode and determine the themes revolving around scaffolding techniques that learners applied in the video blog project. The themes were co-constructed with data collection. Validity and reliability were achieved through peer reviewing from experts and practitioners. Collection of data and transcribing were concurrently done with data analysis.

\subsection{Ethical Concerns}

To address the ethical concerns of this study, participants' identities and their educational institution are kept anonymous, hence the participants were given pseudonyms to protect their identities.

\section{Findings and Discussions}

First, the findings were derived from a qualitative document designed for learners to record their feedback and guide the peer reviewing discussions. The researchers observed, listened and made field notes of the participants' review of their peers' speech to evaluate the video blog. The second part of the findings involves data collected from the focus group interview at the end of the study.

\subsection{Observations of Peer Reviewing Discussions}

\subsubsection{Sensory Scaffolding}

Theme 1: Feedback on structures of language
I: Okay when you say something (referring to her claim about her partner's language was incorrect) you have to support it with another idea (Give examples). Like why do you like it? ... Any words maybe? Pronunciation maybe? Repeated words?

Felix: No, but some sentences I could not understand, she used past (Future?) and present together in one sentence, but I don't know... it's correct or not.

I: Can you read me the sentence?

Felix: People will envious when we saw people driving the...

I: So the error is in?

Felix: I think... let's see, will look envious, it should be people WILL ENVY US when THEY SEE us...

The first form of scaffolding that was observed was an attempt to discuss about grammar or structure. Participants of this study are non-English majors. This discussion shows that a few learners may have adequate knowledge of the language to enable them to identify errors in speech and give feedback.

This is regarded as scaffolding because it involves a knowledgeable individual who could analyze and construct feedback to rectify a language error commonly done by teachers or experts of the field. For example, feedback on the errors committed in grammar with regards to the use of the modal 'will' followed by an adjective 'envious' was given by the participant. Secondly, the error is the use of the wrong pronoun, 'we' referring to 3rd person point of view, which should have been replaced with 'they'.

\section{Theme 2: Addressing pronunciation errors}

I: How can she improve from her video?

Isolde: Maybe pronunciation... umm the /offerings/. /brands/... /creators/, and /import/. Overall she did okay.

Marry: She introduced about contact lens. And it's the brand from Korea. And one with color and one is normal. Ahhh... which one is more /comfortable/. She didn't say which one. She can improve pronunciation. Words like /uncomfortable/.

Scaffolding during this peer reviewing session is in the form of a simulated feedback. A participant reviewed the pronunciation mistakes of certain words that were wrongly pronounced in the video. The observation revealed that some learners exhibit a degree of phonetic awareness and are able to give useful feedback by demonstrating the correct way of pronouncing the words to their peers. This type of scaffolding is introspective and reflective to the learners as they learn through observation and self-reflection.

\section{Theme 3: Rehearsed pronunciation feedback}

I: What do you think she can improve in her video? Any words that wasn't clear to you?

Ell: Maybe pronounce...For example, /than/, pronounce /then/ and Ringgit... she pronounced $/ 3.55 / \ldots$ 
I: How did she pronounce it?

Ell: She said three-point-five-... fifty five...

I: How should she pronounce it then?

ElI: /Tri: RINGGIT FIFTY faiv sent/!"

This discussion displays another type of scaffolding interaction between learners. One participant was the knowledgeable peer who managed to identify the pronunciation errors made by his/her peer and then the participant demonstrated the correct way of pronouncing figures in English with accuracy. At this point, it is also revealed that the purpose of the interaction was fulfilled when learners attempted to simulate and generate feedback that could benefit his/her peer. Although the feedback was just a simple notion, it showed that learners actively participated in learning by observing and reflecting.

\section{Theme 4: Review on pronunciations}

I: Any language part that she can improve? .....

Karen: Maybe on the pronunciation of psi, how to pronounce it / prikatik...psi ... /

I: What are you trying to say here? ...

Lee: / Psi-cha-tirk /, but I keep pronounce it wrong / Psichraa-tic/

I: Okay it's actually like this, / psi.chai.tric /. Alright, good. You address the pronunciation part... aaa anything else, what can she improve in her video in her speech?

Lee: Also like the pronunciation part some word like /vandalism/,/self-esteem/, /authorities/, /deliberate/ and /eradicated/. (Struggling in pronouncing some of the words)

I: okay can you say those words now Karen?

Karen: /Slef;istimee/. /Ortorities/, /deliberate/, /eradicated/...

I: *rehearse the words together with the learners*

During this observation, pronunciation errors committed in the video blog were addressed by the participant. However, there was a problem with rehearsing the correct pronunciation of the word 'psychiatric'. Thus, in order to scaffold the accuracy of pronunciation, the researcher assisted with rehearsing the pronunciation so the learners could learn the accurate pronunciation. The presence of the researcher also helped to facilitate learners upon reviewing their speech. The next example of the peer reviewing sessions explained how learners interact with one another to scaffold learning.

\subsubsection{Interactive Scaffolding}

In this section of findings, the researcher found that learners interact to negotiate meaning. When meaning is concerned, vocabulary becomes the measure. Learners are already familiar with some vocabulary items while others need to be contextualized. When such gap exists, learners will interact and discuss with each other about what the intended meaning was and comprehension was achieved to close the gap. The discussions demonstrate how scaffolding took place in regards to vocabulary and meaning.

Theme 1: Negotiating for context or intended meaning

Glenn: Hannah is talked about social indifference.

I: Social indifference? Okay what's that? What do you understand about that word? Did you ask?

Ss: ... (long silence)

I: I still don't understand what social indifference is. So what is it? Can you explain? Can you give one example? Maybe...Example between you and her. Just an example, what do you mean?

Ss: (talking in a Chinese dialect/ Code Switching)

Glenn: Like for example, a grandmother (talking in a Chinese dialect to Hannah) fall down, then no people came to help. Another example is when people don't want to give pregnant lady a seat in the LRT.

The reviewer explained that the vlogger used an unfamiliar word which is 'social indifference'. This phrase is contextualised and the researcher probed by asking what the vocabulary means to the participants. The participants discussed through code switching in their mother tongue. They tried to come up with the best example to reflect their understanding of the phrase 'social indifference'.

A participant came up with an example of this phrase used earlier during the discussion, which then helped clarify the intended meaning. At this point, it is worth noting that scaffolding took place in the form of semantic negotiation between learners. It was observed that learners sometimes code-switch and discuss the meaning to enable them to explain better with sufficient details using the target language. The researcher encouraged learner interaction and concluded that scaffolding techniques were employed.

I: And the fake news is about kidnapping?

Ell: Yea the fake news is about kidnapping.

I: Okay... and then 70 people died? How did they die? Can you explain? How did they die? Were you listening to the video?

Felix: Yea but don't understand.

I: Okay Ell.. Can you?

Ell: The news is about "Don't Let the Strangers Come into Your Village" and this one (news) will scared the villagers so the thing is can harm them whenever there are some, what we say, aaa strangers or unfamiliar face came into their village, they try to attack them because they think the people are going to kidnap their child.

I: I see, so that's how the fake news caused the death of the 70 people?

Felix: Yes!

At some point of the discussion, it was observed that there was a miscommunication and participants addressed the problem. This could only be achieved when learners give full attention to their peer's speech. During the discussion about their video blog it was observed that a participant was asked to explain the actual intended 
meaning. The participant then summarized the actual message to scaffold comprehension. This type of peer-scaffolding is vital to build up oral fluency not only to the speakers but also to the listeners because avoiding misunderstanding or miscommunication is key to an effective communication. A fluent speaker should be able to deliver messages effectively with clarity and minimum obstructions.

\subsection{Scaffolding in Video Blog Project}

The researchers interviewed the participants after 7 video blog projects to find out their views of the project. Some participants indicated that they prefer collaborating with their peers while others prefer working individually for various reasons.

Theme 1: Participants' views of scaffolding

Probe: Do you prefer recording the video alone or together with your friends, why?

Aaron: I prefer recording a video with my friend because I have a friend that could help me out if there are mistakes and someone to be with. Talking to someone helps me with my communication because I could learn so much more from talking and I could realize the grammar mistakes I made and correct them.

Cindy: It will help us not to be shy because some of us do not usually talk in English. Also, it will improve our confidence for presenting something when talking English.

Felix: I think I prefer doing video recording with someone, because it is more interesting than doing by alone. Yes, talking to someone helps me improve my communication. Because when communicating with others, I can understand more about the different people's thinking patterns.

Glenn: I think video recording with someone else is better than alone because it is better to talk and discuss with someone about something, It makes me more comfortable to have a companion.

The responses above show participants' preferences when working on their video blog project. One of the tasks specifically required them to record a video conversing with a friend using the target language. The purpose of this task is to observe learners' interaction and compare the outcome with their individual video blog tasks. This group of participants clearly demonstrated that they would rather work with peers than completing the task individually.

One of the participants indicated that working together has made them become more aware of their mistakes. Another participant described peer scaffolding as useful to assist in overcoming shyness due to the fact that the participants are non-native speakers of the language and exercising communication with peers helps them overcome their anxiety when using the target language.

Theme 2: Participants who do not prefer scaffolding

Probe: Which do you prefer? Recording alone or with a friend? State your reasons.

Betty: I always think about recording alone is better because I feel a little shy when having conversation with other people.

Isolde: I think video recording alone makes me feel more comfortable compared to video recording with someone, because I think I'm a very shy person.

Penny: No, I think video recording alone is better. I prefer alone because if I'm talking with someone else I will get more nervous than recording alone but it is a good experience.

From another perspective, the group of participants explained that they do not prefer recording with their peers in the video blog project for several reasons. The first participant claimed to feel a little shy when conversing with others. Similarly, another peer explained to the researcher that recording alone makes her more comfortable as compared to paired vlogging.

Lastly, recording with someone has been linked to intensified nervousness by the last participant. The feedback gathered has helped the researcher to understand that some learners accept scaffolding in communication while others are not keen on the idea.

\subsection{Focus Group Interview}

A focus group interview was conducted with 7 randomly selected participants. A thematic analysis of the interview data was carried out. The following themes were identified;

\section{Theme 1: Roles of peers in scaffolding second language acquisition}

Aaron: I think my friend helps me improve my vocabularies when I discussed about the video, he correct my mistake. My friend also helps me improve my pronunciation in then speech when I discussed about the video, because he also teach me. He help me improve my grammar as I ask he want to use past tense or not before we start the video, and he also motivate me improve my language better.

Cindy: Yes, my friend did help me to improve my vocabularies by giving advice to me. My friend helps me a bit my pronunciation by telling me that my video is hard to listen. Yes, my friend also helps me to improve my grammar by direct telling me which word can or can't use. My friend feedback did help me a lot on improve my language because it made me more confident to speak in English.

Daniel: Yes, my friend helps me improve my vocabularies when you discussed about the video. Yes, my friend helps me improve my pronunciation in the speech when I discussed about the video. She let me know the correct of the pronunciation. Yes, my friend helps me improve my grammar in the speech when I discussed about the video. She will help me to correct it my wrong grammar, if she found I'm doing wrong. Yes, my friend's feedbacks 
on video motivate me to improve my language better. Because I can from that to know myself better, it help me improve myself.

Felix: First of all, improve my vocabularies I think $\mathrm{Mr} X$ did a good job who list it out my error and mistake which should be noted down some minor or vocabulary that help me in the future. Next, compare to my partner, she also sometimes make some wrong pronunciation which I could figure out that I also used to make the same mistake. So I could let her know. Thirdly, among of these there's no doubt that my grammar aren't good as speak or even writing because for me grammar sometimes is confusing stuff to make it understand so in this process I would rather list out the error of pronunciation and vocabulary. Lastly, of course, when taking the video till share both of us video, it help me to reflect and know what I also made the same mistake too sometimes.

The above feedback indicates that peer scaffolding has helped the participants improve their vocabulary through discussion and consultation (advice). This opinion was shared by three participants of the study and they also opined that peer scaffolding has helped them improve in terms of pronunciation and grammar. Feedback was generated through peer interaction practices such as discussing, negotiating and consulting.

It was made more apparent by the participants of the peer role in this project when they informed the researcher of how their peers have motivated them to improve, to be more confident when using the language especially in Speaking. However, it was not specified by the participants to what extent they were being motivated or how they were motivated to speak English. Participant in this group also expressed that video production and video reviewing helped them to reflect and to become aware of the errors committed in their respective videos. This finding shows that video blogging has the ability to encourage learners to self-assess and self-reflect on their performance, and peer collaboration further amplifies this through reviewing.

Theme 2: Limitations of peer roles to scaffold second language acquisition

Glenn: No, because we are amateur in grammar, so we can't solve the problem by us, we ask Google. Yes, sometimes he use the vocabularies very well, it is benefit to me when I have presentation.

Betty: Not really, because we were listening the video and write it down separately so didn't have time to talk about that. Honestly, both of us are not good in grammar we are still learning. Yes it did not, they tell me to be more confidence when I talk.

Ell: No, my friend didn't help me improve my vocabularies when I discussed about the video, because he is not so good at English. We just only discussed with some point. No, I think my friend didn't help me improve my pronunciation in the speech when I discussed about the video. Because we practice separately. Yes, my friend helps me improve my grammar in the speech when I discussed the video. She will remind me when I don't know about it. No, my friend's didn't feedback or video motivate me to improve my language better, because she didn't say anything

Some participants were not convinced of the role of peer scaffolding as it was deemed insufficient. One participant claimed that both she and her partner in the vlog project were not good in grammar. Therefore, they were not able to produce sufficient feedback to help each other learn. Relating back to the principle of scaffolding by Vygotsky, in order for learners to grow and learn what is beyond their present abilities, there must be sufficient scaffolding received by the learners to stimulate learning and enable the acquisition of new knowledge or skills. This feedback shows that when learners were not paired with someone who has the competency in language, they are not likely to find peer scaffolding as helpful as it was hoped for in the study. When such problem arose, learners resorted to other sources for help such as the internet to supply them with the information they needed.

Additionally, another participant also commented that they were not interacting much when completing the video blog task. This could be due to the clash in schedules or their preference to work individually. It was never explained by the participant to the researcher. The only indicator is they did not have time to sit down and discuss what went wrong or what should be improved in future tasks. Moreover, two participants shared the same view as they claimed to be incompetent in grammar. As a result, they were not able to generate useful feedback such as corrective feedback to improve on the language used.

Another participant concurred that peer scaffolding did not really help them improve in terms of language use such as vocabulary enrichment due to a similar factor, which is because both the participant and her peer were not proficient in the language. Thus, it is noted by the researcher that peer scaffolding was not successful because the pairing system of the participants was not well executed in the study. It was also found that the participant did not benefit from his/her peer in terms of language development such as pronunciation awareness because they were practicing separately. However, the participant claimed that he improved in grammar use during the discussion of the video during the peer-reviewing session. Lastly, the participant concluded that no form of motivation or encouragement was received from his/her peer.

\subsection{Discussion}

Sharples and Domingue (2016) posited that opportunities to practice and receive feedback from tutors or peers under realistic conditions are limited although it is possible to attend courses on public speaking. However, the findings in this study proved that learners can manage and generate feedback to facilitate learning through 
blended and task based learning using a video blog project.

The study conducted by Gorkaltseva et al. (2015) found that learners' low motivation for verbal interaction, which resulted from learners' lack of pragmatic competence and lack of linguistic competence, caused oral fluency to be severely hindered. Linguistic competence may be attainable through formal instruction. However, in the case of pragmatic competence, learners can develop their competency in communicating through various means with the aid of technology. Findings from this study revealed that motivation may not exactly be the main challenge for learners to interact verbally, but rather task designs that are appropriate and can stimulate interaction. Participants of this study actively participated in learning through creating the vlog portfolio, exercised their spoken English, assessed and reflected their performances. The design of the task gives heavy emphasis on learner accountability and autonomy in their own learning. Thus, self-directed learning can be achieved with suitable task designs that cater to different instructional needs.

Gromik (2015), Chen (2006) and Pertaub et al. (2002) contended that EFL learners do not have adequate opportunity to use the language during non-contact class time. However, technology and blended pedagogy today have allowed learners and instructors to maximize interactivity in learning. Inadvertently, opportunities to use the language beyond the classroom have become feasible. The concepts of ZPD (Vygotsky, 1978) and connectivism (Siemen, 2008) that underpin this study support the need for scaffolding, connectivity and social networking to accelerate language learning. Teachers play an important role in bringing the language rich environment to the classroom to achieve an optimal learning condition.

\section{Conclusions}

Peer support or scaffolding indeed holds a certain influencing factor to the participants. It was indicated that participants of this study felt comfortable from the support they received from their peers and reduced anxiety. Comparisons of participants' preferences showed that peer interaction has a positive outcome for learners. Therefore, conducting tasks with the presence of peers does play a role in learners' success of completing the project, besides topic familiarity and the video blog as a learning tool itself that encourages participants to continuously practice their English to form a behavioural pattern. This then resulted in progress in the ZPD through acquiring and learning new skill sets and linguistic knowledge. Strong presence of behavioural scaffolding using technology was found in this task. This resonates strongly with the concepts of ZPD and connectivity.

\section{REFERENCES}

[1] Abdelraheem, A. Y., \& Ahmed, A. M. (2018). The impact of using mobile social network applications on students' social-life. International Journal of Instruction, 11(2), 1-14.

[2] Alias, M., Sidhu, G. K., \& Chan, Y. F. (2013). Unemployed Graduates' Perceptions on Their General CommunicationSkills at Job Interviews. Procedia - Social and Behavior- al Sciences, 90, $324-333$.

[3] Alvarez, C., Alarcon, R., \& Nussbaum, M. (2011). Implementing collaborative learning activities in the classroom supported by one-to-one mobile computing: A design-based process. Journal of Systems and Software, 84(11), 1961-1976.

[4] Bakar, N., \& Ismail, K. (2007). Using Blogs to Encourage ESL Students To Write Constructively In English. Nadzrah Abu Bakar Kemboja Ismail, 1(1), 45-57.

[5] Chiang, T. H., Yang, S. J., \& Hwang, G. J. (2014). An augmented reality-based mobile learning system to improve students' learning achievements and motivations in natural science

[6] Cresswell. (2014). Researh Design: Qualitative, Quantitative, and Mixed Methods Approaches.

[7] Chen, Y. (2006) 'Barriers to Acquiring Listening Strategies for EFL Learners and Their Pedagogical Implications', TESL-EJ, Vol. 8 (4), pp. 1-25

[8] Daniels, H. (2001) Vygotsky and Pedagogy. NY: Routledge/Falmer.

[9] Darmi, R., \& Albion, P. (2013). English Language in the Malaysian Education System: Its Existence and Implications. 3nd Malaysian Postgraduate Conference (MPC2013), 2(July 2015), 3-4.

[10] Donnelly, R., \& Fitzmaurice, M. (2005). Designing Modules for Learning. Emerging Issues in the Practice of University Learning and Teaching, 99-110.

[11] Ferdig, R. E., Pytash, K. E., Kosko, K.W., Gandolfi, E., \& Mathews, R. (2016). Use and perceptions of mobile applications and technologies by those interested in special education. Kent, OH: Kent State University.

[12] Gorkaltseva, E., Gozhin, A., \& Nagel, O. (2015). Enhancing Oral Fluency as a Linguodidactic Issue. Procedia - Social and Behavioral Sciences, 206(November), 141-147.

[13] Gromik, N. A. (2015). The Effect of Smartphone Video Camera as a Tool to Create Gigital Stories for English Learning Purposes. Journal of Education and Learning, 4(4), 64.

[14] Hammond, J. (Ed.) (2002). Scaffolding Teaching and Learning in Language and Literacy Education. Newtown, Australia: PETA 177

[15] Hassan, F., \& Selamat, N. F. (2002). "Factors that Contribute to the Learners ' Speaking Problem, 1999-2001.

[16] Hiew, W. (2012). English Language Teaching and Learning Issues in Malaysia: Learners' Perceptions Via Facebook Dialogue Journal. Journal of Arts, Science \& Commerce, 3(1), 11-19. 
[17] Hsu, H. Y., Wang, S. K., \& Comac, L. (2008). Using Audioblogs to Assist English-Language Learning: An Investigation into Student Perception. Computer Assisted Language Learning, 21(2), 181-198.

[18] Hung, S. T. (2011). Pedagogical Applications of Vlogs: An Investigation into ESP Learners Perceptions. British Journal of Educational Technology, 42(5), 736-746

[19] Hussain, I., Cakir, O., \& Candeger, Ü. (2018). Social media as a learning technology for university students. International Journal of Instruction, 11(2), 281-296.

[20] Insyirah, H., Sukri, M., Mustapha, L., Othman, M., Aralas, D., Ismail, L., Othman, M. (2018). Social Media : Engaging Language Learning Social Media: Engaging Language Learning, 8(12), 287-294.

[21] Jap, S. D. (2007). An Exploratory Study of The Videoblogger's Community, (January), 92.

[22] Kessler, G. (2018). Technology and the future of language teaching. Foreign Language Annals, 51(1), 205-218.

[23] Lim, J. B. Y. (2013). Video blogging and youth activism in Malaysia. International Communication Gazette, 75(3), 300-321.

[24] Malita, L., \& Martin, C. (2010). Digital storytelling as web passport to success in the 21st century. Procedia - Social and Behavioral Sciences, 2(2), 3060-3064.

[25] Nguyen, M. H. (2013). EFL Students' Reflections on Peer Scaffolding in Making a Collaborative Oral Presentation, 6(4), 64-73.

[26] Pertaub, D.-P., Slater, M., \& Barker, C. (2002). An Experiment on Public Speaking Anxiety in Response to Three Different Types of Virtual Audience. Presence: Teleoperators and Virtual Environments, 11(1), 68-78.

[27] Ranjbar, N., \& Ghonsooly, B. (2017). Language Teaching Research Peer Scaffolding Behaviours Emerging In Revising A Written Task: A Micro-genetic Analysis, 5(June), 75-90.

[28] Remesh, A. (2017). Curriculum Design Principles For Developing A Module In Medical Education. Progress in Medical Sciences, 1(1), 34.

[29] Richardson, W. (2009). Blogs, Wikis, Podcasts. Thousand Oaks, California: Corwin Press.

[30] Shahariah Saleh, N., \& Murtaza, S. F. (2018). English Language Use in Malaysian Government and Private Civil Engineering Workplaces. International Journal of Education and Literacy Studies, 6(3), 84.

[31] Sharples, M., \& Domingue, J. (2016). Adaptive and Adaptable Learning. Lecture Notes in Computer Science. Switzerland, 9891, 13-16.

[32] Siemens, G. (2005). Connectivism: A Learning Theory for the Digital Age. International Journal of Instructional Technology and Distance Learning, 2, 1-9.

[33] Siemens, G. (2008). A Learning Theory for the Digital Age: Connectivism. Digital Age, 1-5.

[34] Stone, A. (1998). The Metaphor of Scaffolding: Its Utility for the Field of Learning Disabilities. Journal of Learning
Disabilities, 3 (4), pp 344-364.

[35] Tanveer, M. (2007). Investigation of the factors that cause language anxiety for ESL / EFL learners in learning speaking skills and the influence it casts on communication in the target language . By, (June), 1-92.

[36] Verenikina, I. (2008). Scaffolding and learning: its role in nurturing new learners.

[37] Vygotsky, L. (1978). 'Mind in Society'. US: President and Fellows of Harvard College.

[38] Wells, G. (1999). Dialogic Inquiry: Towards a Sociocultural Practice and Theory of Education. New York: Cambridge University Press.

[39] Gustafsson, J. (2017). Single case studies vs. multiple case studies: A comparative study.

[40] Yin, R. K. (1994; 2003; 2009). Case study research: Design and methods. Thousand Oaks, CA: Sage.

[41] Yunus, M. M., Nordin, N., Salehi, H., Embi, M. A., \& Salehi, Z. (2013). The use of information and communication technology (ICT) in teaching ESL writing skills. English Language Teaching, 6(7), 1-8. 